\title{
Performance Evaluation and Parameter Optimization of Moving Bed Biofilm Reactor (MBBR) along with Electrocoagulation for Removal of Azithromycin
}

\author{
Nadeem A. Khan 1(D), Sirajuddin Ahmed ${ }^{1}$ (D), Izharul Haq Farooqi ${ }^{2}$ (D), Imran Ali ${ }^{3}$ (D) \\ 1 Department of Civil Engineering, Jamia Millia Islamia, New Delhi-110025, er.nadimcivil@gmail.com (N.A.K.); \\ 2 Zakir Hussain College of Engg and Technology, Civil Engineering Department, Aligarh Muslim University, India-202002, \\ ksaifullah.cv@amu.ac.in (I.H.F.); \\ 3 Department of Chemistry, Jamia Millia Islamia, New Delhi-110025, drimran.chiral@ gmail.com (I.A.); \\ * Correspondence: er.nadimcivil@gmail.com (N.A.K.);
}

Scopus Author ID 56035431400

Received: 1.06.2021; Revised: 1.07.2021; Accepted: 4.07.2021; Published: 9.07.2021

\begin{abstract}
Antibiotics from hospital discharge wastewater are known to be one of the most significant water contaminants. Environmental researchers suggest the attainment of effective and biological approaches for the elimination of these contaminants. This work aims to study the efficiency of an azithromycin (AZX) removal using moving bed biofilm reactor (MBBR) combined with electrocoagulation and parameters optimization using a response surface methodology for hospital wastewater (RSM), i.e., MLSS (A), pH (B), HRT (C) and Electrode distance (D). The present research was conducted using PVC gel on a pilot scale for removing a detergent from the wastewater of hospital reactors with continuous hydraulic flux. The impact on the device concentration of independent variables, including duration of touch, percentage of the media, and the concentrations of 1200-3200 $\mathrm{mg} / \mathrm{l}$ of mixed liquor suspended solids (MLSS). Closed laboratory procedure for measuring AZX concentration, azithromycin (AZX), and chemical oxygen requirement (COD) 1500-2400 mg/l is used. The findings showed that AZX and COD with PVC gel retention times are 92.3 and 95.8 percent, respectively, of 24 hours, with an MLSS concentration of approximately 3,200 mg/l. It was shown that the MBBR device has great productivity in detergent deletion from hospital waste wastewater as a biofriendly compatible process and can produce regular performance effluents at an appropriate period. The experiment was performed using an electrochemical process, electrolysis with independently variable electrical electrodes, i.e., voltage, duration of touch, and electrolyte concentration. The complete process was optimized for the said reaction using Design-Expert software. The response surface method was used to optimize the operational parameters and show that a contact period of 35 minutes, voltage $12 \mathrm{~V}$, electrolyte concentration of $0.35 \mathrm{M}$ with electrode distance $1.25 \mathrm{cms}$ gives $89 \%$ removal efficiency. The model for the three variables recommended by the response surface is a quadratic response.
\end{abstract}

Keywords: response surface methodology; hospital wastewater; electrochemical process; optimization; moving bed biofilm reactor; azithromycin.

(C) 2021 by the authors. This article is an open-access article distributed under the terms and conditions of the Creative Commons Attribution (CC BY) license (https://creativecommons.org/licenses/by/4.0/).

\section{Introduction}

Often antibiotics are poorly disposed of in aquatic and soil habitats [1]. The body is not metabolized entirely by antibiotics, always active 30-90\% until excreted [2]. As mentioned, the permissible minimum dose of antibiotics in wastewater is $1 \mathrm{mg} / \mathrm{l}$ in the United States 
Environmental Protection Agency (USEPA) [3]. A lot of people [4]. Researchers have sought appropriate treatment methods for wastewater involving these drugs [5]. The critical processes for wastewater are Physicochemical and biological methods Therapy [6]. Biological processes are cheap, while removing resistant organic matter from waste wastewater is not successful [7]. Instead, the physicochemical-chemical processes will achieve high efficiency and high waste wastewater quality, although they are expensive [8]. However, it is not necessary to treat high concentration waste wastewater alone by physicochemical-chemical or biological methods [9]. Several biofilm technologies, including trickling filters or biological contactors, biofilters, granular bed biofilters, and fluidized bed reactors, are available for the biological processes of wastewater treatment, all with some advantages and advantages [10]. The wastewater treatment device (MBBR) was built 30 years ago [11]. The main advantage of MBBR is that it can accumulate biomass and biofilm in the reactor allowing a wide range of microorganisms to be present [12]. In general, advances in oxidation processes are the most effective technologies for decomposing and eliminating dangerous, resistant, and boring reactors [13]. In this system, the reactor provides an area for the growth of microorganisms, and aquatic environmental shows the presence of different chemical compounds[14]. Many composites, including hydrogen peroxide (UV) activation, photocatalysis, Magnetic composite with activatedcarbon, bagasse cane adsorption, sulfate photocatalytic degradation radicals, show good removal efficiency towards the pharmaceutical wastewater [15]. Rapid reaction rates, low footprint, reduced toxicity capacity, and the mineralization of oxidation processes include Chemical waste not concentrated by some methods for further processing (e.g., membranes, not substance requiring further treatment) [16].

Further, the treatment of pharmaceutical wastewater using physical, chemical, and biological processes is nowadays in the development stage, and many combinations are used for it [1]. The restrictions of the advanced on the other side processes for oxidation include capital cost, advanced chemistry that helps in degradation to a particular compound, and bynature of by-product formed after treatment [17]. Advanced oxidation in recent decades processes was commonly employed to achieve a good efficacy in water and wastewater treatment [18]. The principal process of these processes are hydroxyl radicals and can quickly and non-selectively oxidize most organic compounds [19].

\section{Materials and Methods}

\subsection{Analytical method used.}

The analysis was performed by evaluating the analytical determinations of carbamazepine, diazepam, ofloxacin, simvastatin, sorafenib, erythromycin, Ibuprofen, diclofenac, and furosemide. This research has been carried out using an automated approach focused on liquid chromatography-MS/MS [20-22]. The following operating criteria apply to analyze specific medication residues: Symmetry shield RT 18, chromatographic column 5 micron, 6x150 mm, ammonium style in water format (A) handheld phases, and methanol format $10 \mathrm{~mm}$ ammonium format (B) all of them produce $0.2 \%$ formic acid [23]. Therefore, a mobile phase A of $20 \%$ and a mobile phase B of $80 \%$ are used as an isocratic program. The flow rate per minute was $0.8 \mathrm{ml}$, and the amount injected was $25 \mu \mathrm{l}$. The testing of the pharmaceutical concentration using UPLC H-Class and Waters Xevo TQ-S Micro liquid chromatography (Tandem Quadrupole Mass Spectrometer). The UPLC detects and quantifies the molecule using positive electrospray ionization (ESI) source [24-31]. By explicitly infusing 
$10 \mu \mathrm{lmin}-1$ of both analytes' solutions, the contingent parameters had been optimized. The next move was to choose the ionization and the ion modes of the precursor. In addition to the corresponding capillary voltage $(4.5 \mathrm{kV})$, cone voltage $(33 \mathrm{~V})$, spring temperature $\left(150^{\circ} \mathrm{C}\right)$ and desolation temperature $\left(450^{\circ} \mathrm{C}\right)$, cone gas flow $(50 \mathrm{l} / \mathrm{h})$, solvent flow $(850 \mathrm{~L} / \mathrm{h})$, collision gas Flow $(50 \mathrm{ml} / \mathrm{min})$, the quantity of automatic quantitative optimization was used for the determination of the ions of substance. Simultaneously, the analytes were monitored for quantification and validation transformations [32-36].

\subsection{Experimental setup.}

Holy Family Hospital in New Delhi City supplied genuine influential wastewater. A 15-liter MBBR reactor with the up-flow and ongoing hydraulic flow was used in this research. In this study, the reactor was made from cylindrical Plexiglas with a total height of $30 \mathrm{~cm}$, an interior diameter of $150 \mathrm{~cm}$, and an efficient capacity of 15 liters. Aerated in the device by the air compressor and via the tubes in the bottom of the reactor, the air needed to provide dissolved oxygen and rotator in the substrate content is entered through a reactor volume.

PVC gel media is used as a bed to investigate the efficacy of the AZX anionic detergent solution in hospital wastewater treatment. This medium was manufactured from $0.96 \mathrm{gr} / \mathrm{cm} 3$ of polyethene (PE), and the growing range was $500 \mathrm{~m}^{2} / \mathrm{m}^{3}$. Raw hospital waste wastewater was fed into reactors by the peristaltic pump with flow rates between 0.001 and $0.003 \mathrm{~L} / \mathrm{s}$ for the required hydraulic retention period in upstream mode (HRT). About $30 \%$ of the reactor volume was initially packed with the media for the reactor's initial installation.

In the secondary sedimentation basin of the hospital treatment station, the reactor was then filled in about a third of its volume with return locks. It was filled with waste wastewater for the remainder of its volume, ensuring discontinuity of reactor operation. This trial had around 2 to $3.0 \mathrm{mg} / \mathrm{l}$ of dissolved oxygen. An automated aquarium heater with a temperature setting of between 22 and 27 degrees was used for the optimum micro organisms' operation and temperature maintenance. The $\mathrm{pH}$ of the hospital waste wastewater was 7.5 to 8.5 . In this analysis, successful factors such as temperature, oxygen dissolved, $\mathrm{pH}$, and other parameters for microorganism behavior were continuously evaluated. Ten weeks after the reactor configuration, substantial biofilm development was shown on the internet, and after this phase, the reactor became constantly modeled to analyses detergent removal under various environments from the hospital wastewater. In this analysis, experiments related to AZX were evaluated in the standard method. Electrodes are prepared up to 2 sets $(300 \times 150 \times 2) \mathrm{mm}$ and then sandpaper. After assembling the instrument for the batch machine, it was placed in the hospital liquid waste up to $1.3 \mathrm{~L}$, which is to be analyzed by electrical voltage $(6 \mathrm{~V})$. Any time 15,30 , and 45time period at varying voltages of 9 and $12 \mathrm{~V}$ with a distance of $1.25 \mathrm{cms}$ was maintained using the iron electrode.

\subsection{Design of experiment (DOE).}

The influencing parameters, namely packing rate, HRT, mixed liquor suspended solids (MLSS) concentration, were considered (Table 1). The influencing parameters used for detecting the system's efficiency in AZX removal (\%) [37-44]. In the current study, for lowering the chemical waste and considering the number of the experimental run, a Central Composite Design (CCD) (one of the RSM family designs) was used to analyze the experiments by Design- Expert 13.0 software. Table 2 attributes to the experimental condition 
during the lab experiment, and the encoded parameters used in the software are shown in Table 3.

Table 1. Influent wastewater characteristics.

\begin{tabular}{c|c|c} 
Parameters & Unit & Range \\
\hline COD & $\mathrm{mg} / \mathrm{L}$ & $1500-2400$ \\
\hline BOD & $\mathrm{mg} / \mathrm{L}$ & $520-1230$ \\
\hline Turbidity & $\mathrm{NTU}$ & $430-540$ \\
\hline Total Suspended Solids (TSS) & $\mathrm{mg} / \mathrm{L}$ & $2430-3700$ \\
\hline Alkalinity & $\mathrm{mg} / \mathrm{L}$ of $\mathrm{CaCO}_{3}$ & $740-1250$ \\
\hline $\mathrm{pH}$ & ---- & $6.4-7.9$
\end{tabular}

Table 2. Operational parameters of EBR.

\begin{tabular}{l|l|l|l|l|l} 
S.No. & Period (days) & $\mathbf{0 - 3 0}$ & $\mathbf{3 0 - 6 0}$ & $\mathbf{6 0 - 9 0}$ & $\mathbf{9 0 - 1 2 0}$ \\
& \multicolumn{1}{|l|}{ Parameters } & & & \\
\hline 1. & Cycle/HRT (Hours) & 24 & 20 & 18 & 12 \\
\hline 2. & $\begin{array}{l}\text { COD loading rate } \\
\text { COD/m } / \text { day) }\end{array}$ & 0.29 & 1.26 & 2.26 & 3.46 \\
\hline 3. & COD removal \% & 82 & 65 & 74 & 80 \\
\hline 4. & Current timing(10millamp) & 20 & 30 & 40 & 50 \\
\hline 5. & MLSS (g/L) & $0.1-0.5$ & $0.5-1.2$ & $1.2-2.0$ & $2.0-3.2$
\end{tabular}

The design expert tailored the experimental conditions (version 13.0). RSM was exposed to the sequential amount of square testing and the absence of a fitness measure utilizing central composite design (CCD). In terms of COD, nitrate, and phosphate elimination percentage, the CCD model was used to consider the interaction between 3 method parameters: MLSS (A), pH (B), HRT (C), and Electrode distance (D). A three-factor and five-level CCD is used for the optimization phase by Design Expert Software. A series of 20 tests have been performed on the answer surface model with fourteen factorial and six axial points and six central points.

As seen below in Table 4, these parameters were encoded. A model recalling the answer is generated using the CCD process. A quadratic equation was observed for analysis in the current study SBR method. ANOVA (Variance Analysis) may be used to approximate the precision of models from experimental results. The statistical indices such as $\mathrm{F}$ value and $\mathrm{P}$ value are seen in ANOVA. If $\mathrm{F}$ has a high P-value (0.05), the model may be seen as statistically significant.

Furthermore, the high value of the correlation coefficient indicates the exactness of the model suggested. For the model to match, the lack of fit should not be necessary. Via 3 D surface graphs compiled with software from Architecture Expert, the answer was compared to two variables, and other variables were maintained constantly. The efficiently removed ratio of the AZX to the 3-D graphics, as seen in Figures 1, 2, and 3, varies between 91.5\%.

Table 3. Coded values for modeling in the RSM model.

\begin{tabular}{c|c|c|c|c} 
Coded values & A: $\mathbf{M L S S}(\mathbf{m g} / \mathbf{L})$ & B: $\mathbf{p H}$ & $\mathbf{C :} \mathbf{H R T}(\mathbf{h r s})$ & D:Electrode Distance $(\mathbf{c m s})$ \\
\hline-2.0 & 1200 & 6 & 6 & 0.5 \\
\hline-1.0 & 1600 & 7 & 10 & 0.75 \\
\hline 0.0 & 2200 & 8 & 12 & 1.00 \\
\hline 1.0 & 2600 & 9 & 14 & 1.25 \\
\hline 2.0 & 3200 & 10 & 18 & 1.50
\end{tabular}

The statistical relevance and interaction of these factors at different probability levels are illustrated in Table 3. A value of 0.9993 was obtained for the deletion efficiency of AZX 
with the determination coefficient $\left(\mathrm{R}^{2}\right)$. This shows that the quadratic model could account for more than $95 \%$ of the total variability. The adjusted AZX deletion regression values were over 0.9986 , indicating that the response to variables had a perfect correlation. The $\mathrm{P}$-value $<0.05$ implies that model terms are significant at 95 percent or higher confidence, while values higher than 0.10 show no significant confidence in model terms. A relatively low value of the model variation coefficient for removing AZX was achieved by 1.3 percent, which means that the experiments were preciseness and reliable. The F-test, which lacks fit, describes the change in the data around the model. Table 3 states that the statistically significant lack of $p$ values of $>0.05$ for removal of AZX implies that the model has a significant correlation with AZX removal variables. Residuals are considered essential to address the model's adequacy, which defines the difference between the observed response values and its expectable value. Typical test plots are graphical tools to demonstrate a straight line of residues. The typical AZX removal probability plot as shown in Figures 3(i) and 3(ii) for almost all set of points is typically spread near the straight line and around the line. In contrast to the anticipated response, the correctness, as well as the accuracy of the model, can be seen from the residual plot. The random dispersal of the residues around nil, as shown in Figures 3(iii) and 3(iv). The models were seen to be well-conducted and satisfy continuous variance assumptions. In addition, the residuals should be dependent on parameters independent in a designed model(s).

\section{Results and Discussion}

A valuable parameter to reduce AZX is the appropriate HRT. The efficiency of MBBR processes has increased by reducing HRT as per the results from this study, which examined the effectiveness of bioreactor in biological degradation of AZX pesticides so that the efficiency of removal by HRT has been increased from $75.5 \%$ to $97.6 \%$ by raising the HRT from 12 to 36 hour (runs 1 and 3). This is presumably because microbial released enzymes may become more effective, and biofilms can be made more bioavailable to food. As the work was conducted at the retention time of $12 \mathrm{~h}$, thereby keeping the flow rate high, biofilm developed late, and the high oxygen content dissolved into the system. This leads to the creation of the shear layer and biofilm detachment is one of the causes for this process. In more significant retention periods ( 24 and $36 \mathrm{~h}$ ), the reactor was stabilized and the generated biofilm layer thickened with a considerable improvement in the biodegradation efficiency of AZX due to the decreased dissolved oxygen and a reduction in feeding into microorganisms (F/M).

In this research, the effectiveness of the MBBR reactor coupled with electrocoagulation in removing COD was improved by raising the HRT from 8 to $24 \mathrm{~h}$, thereby boosting COD elimination efficiency from 73.4 to 95.1. Similarly, the findings of the MBBR investigation on aniline retrieval also indicate that the greatest HRT $(72 \mathrm{~h})$ aniline removal efficiency is achieved. Furthermore, the findings demonstrated that the MBBR effectiveness in formaldehyde elimination had been boosted significantly by increasing HRT.

The processing efficiency of biofilm reactors relies mainly on the amount of access to microorganisms' development connected to the features and filling fractions of the carrier. The biomass accumulation thus directly affects the creation of bacteria in the bioreactor. Increasing the bacteria leads to increased biofilm formation and hence influences removal. In this research, the removal effectiveness of AZX as the biomass rose from 25 to $75 \%$ (Figure 1) such that the removal efficiency of AZX from 68.9 to 97.66 percent by increasing the biomass to 25 to 75 percent (Runs 1 and 5). In the investigation on BOD and MBBR removal, a low filling fraction 
has been observed to positively influence removal efficiency, and the process efficiency is enhanced with the increased filling fraction.

Further, the results showed that the AZX efficiency increased by increasing the MBBR from 30 to 70 percent due to increased media up to a limit. The efficiency increased from $30 \%$ to 51 percent when we clubbed with electrocoagulation. The effectiveness of the reactors in the removal of pollutants is substantially less than the biological system alone. The findings demonstrated an inverse connection between AZX input and removal efficiency (Figure 1); hence, the efficiency of elimination was reduced from $97.66 \%$ to $52.6 \%$ by increasing MLSS concentration from 10 to $50 \mathrm{mg} / \mathrm{L}$ (Runs 1 and 2) (Table 1), similar with research findings done in the past. The AZX biodegradation process's research findings have shown that the AZX removal efficiency has been boosted by a decrease of MLSS such that a concentration of 0.01 $\mathrm{mg} / \mathrm{L}$ of most excellent efficiency has been achieved (96 percent). This research used 1000 times the lowest concentration of AZX. The most efficient AZX elimination in HRT of $36 \mathrm{~h}$, $10 \mathrm{mg} / \mathrm{L} \mathrm{AZX}$, and a 75\% filling percentage were reported in Table 1. According to data given in Table 1. Therefore, the AZX concentration was near the maximum recommended concentration in the MBBR reactor outlet ( $0.08 \mathrm{mg}$ per liter) (International Joint Commission, Canada, and the United States 1977), which is lower than the standard if low levels of AZX are used. Under these conditions, the AZX concentration was about $0.23 \mathrm{mg} / \mathrm{L}$.

Factor $\mathrm{C}$ had the most considerable effect on removal performance based on Eq. 5 for azithromycin, although factor $\mathrm{AB}$ had the most negligible impact. In addition, the least essential influence was found in the HRT between the three significant research variables. The positive and negative signs showed that the tested parameters and their reaction were directly and inversely related. During this analysis, three single effects words were deemed necessary, i.e., A, B, and C, and two dual efficacy terms ( $\mathrm{AB}$ and A2) $(\mathrm{P}<0.0500)$. Table 4 displays the RSM-based benefit of antibiotic removal during the experimental process. In the response surface methods for azithromycin removal by MBBR scheme, findings of linear regression analyses for the 2FI model are shown in Table 3. The ANOVA findings of the 2FI model concerning azithromycin removal using the MBBR method are shown in Table 4.

\subsection{Effect of MLSS and HRT in the removal of AZX.}

Tables 5 and equation 1 show the outcomes of this step of the experiments. In this step, the results of the azithromycin removal efficiency at a concentration of MLSS (1,200 to 3,200 $\mathrm{mg} / \mathrm{l})$ were examined. The increased azithromycin removal efficiency was correlated, according to the results, with higher MLSS concentrations. The MLSS concentration of 1000 $\mathrm{mg} / \mathrm{l}$, HRT 04, 08, and 12 hours, and the packaging levels of $20 \%, 40 \%$, and $60 \%$, showed that azithromycin was $28 \%, 47 \%$ concentration of MLSS, the rate of elimination was calculated at $3,200 \mathrm{mg} / \mathrm{L}$ was $91.2 \%$, according to the findings of this analysis. The optimal concentration of this MLSS concentration was then chosen. Biofilm development and the number of microorganisms may be due to the high device performance. In this respect, Shokoohi et al. researched the removal of AZX anti-zero anion detergent from wastewater hospitals utilizing the MBBR, which proposed similar findings and thus improved efficiency of removal at higher RSM concentrations. Azithromycin efficiency was 34\%, 55\% (14\%), and HRT of $12 \mathrm{~h}$, with azithromycin elimination efficiency of $39 \%$ and $61 \%$, respectively., and $91.2 \%$.

Consequently, azithromycin was 91.2 percent at the 12-hour HRT for its highest removal efficiency. The HRT was thus chosen as the optimum HRT of 12 hours. The performance of the MBBR method in lowering urban wastewater AZX was further studied by 
Golshahi et al. in comparison to traditional active sludge systems, and the findings were comparable. The higher removal performance of urban wastewater AZX was therefore correlated with an improved HRT. In addition, the efficiency was close to the eight hours and 12 hours of the HRT in removing AZX. The 8-hour HRT was thus selected as the optimal retention time due to the higher energy consumption savings in oxygen tanks or mixers.

Table 4. ANOVA Model with significant values

\begin{tabular}{l|l|l|l|l|l|l} 
Source & Sum of Squares & df & Mean Square & F-value & p-value & significant \\
\hline Model & 1540.81 & 14 & 110.06 & 63.20 & $<0.0001$ & \\
\hline A-MLSS & 14.51 & 1 & 14.51 & 8.33 & 0.0113 & \\
\hline B-pH & 142.59 & 1 & 142.59 & 81.88 & $<0.0001$ & \\
\hline C-HRT & 0.4483 & 1 & 0.4483 & 0.2574 & 0.6193 & \\
\hline D-Electrode distance & 109.74 & 1 & 109.74 & 63.02 & $<0.0001$ & \\
\hline AB & 93.32 & 1 & 93.32 & 53.58 & $<0.0001$ & \\
\hline AC & 212.43 & 1 & 212.43 & 121.98 & $<0.0001$ & \\
\hline AD & 34.11 & 1 & 34.11 & 19.58 & 0.0005 & \\
\hline BC & 105.27 & 1 & 105.27 & 60.45 & $<0.0001$ & \\
\hline BD & 88.83 & 1 & 88.83 & 51.01 & $<0.0001$ & \\
\hline CD & 61.47 & 1 & 61.47 & 35.30 & $<0.0001$ & \\
\hline $\mathrm{A}^{2}$ & 3.91 & 1 & 3.91 & 2.25 & 0.1546 & \\
\hline$B^{2}$ & & & & & & \\
\hline$C^{2}$ & 333.80 & 1 & 333.80 & 191.68 & $<0.0001$ & \\
\hline $\mathrm{D}^{2}$ & 290.79 & 1 & 290.79 & 166.98 & $<0.0001$ & \\
\hline Residual & 30.25 & 1 & 30.25 & 17.37 & 0.0008 & \\
\hline Lack of Fit & 26.12 & 15 & 1.74 & & & not significant \\
\hline Pure Error & 20.51 & 10 & 2.05 & 1.83 & 0.2623 & \\
\hline Cor Total & 5.61 & 29 & 1.12 & & &
\end{tabular}

Table 5. Fit statistics.

\begin{tabular}{l|l|l|l|l} 
Std. Dev. & 1.32 & & $\mathrm{R}^{2}$ & 0.9833 \\
\hline Mean & 76.50 & & Adjusted R & 0.9678 \\
\hline C.V. \% & 1.73 & & Predicted R & 0.9194 \\
\hline & & Adeq Precision & 33.8367
\end{tabular}

The value obtained from the model shows a Predicted $\mathrm{R}^{2}$ of 0.91 and an Adjusted $\mathrm{R}^{2}$ of 0.96 , showing the difference of 0.2 , which attributed good significance to the model. A ratio greater than 4 is desirable. The ratio of 33.8 indicates an adequate signal. This model can be used to navigate the design space.

Obtained optimized equations using independent parameters were shown in equation (i)

Azithromycin removal \% $(\mathbf{A Z X})=80.7517+0.7775 \mathrm{~A}+2.4375 \mathrm{~B}+0.136667 \mathrm{C}+$ 2.13833 D + -2.41 AB +3.64 AC-1.46 AD-2.56 BC+2.36 BD-1.96 CD + 0.377 $\mathrm{A}^{2}+-$ $3.48854 \mathrm{~B}^{2}+-3.25604 \mathrm{C}^{2}+1.05021 \mathrm{D}^{2}$

The equation (i) in terms of coded factors can be used to predict the response for given levels of each factor. By default, the high levels of the factors are coded as +1 , and the low levels are coded as -1 . The coded equation helps identify the relative impact of the factors by comparing the factor coefficients. 


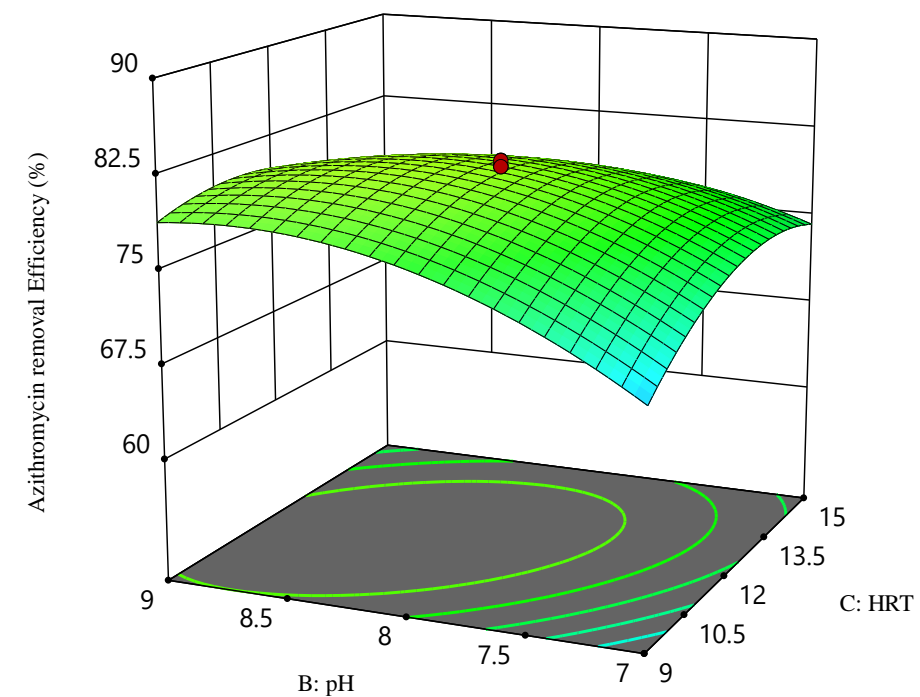

(i)

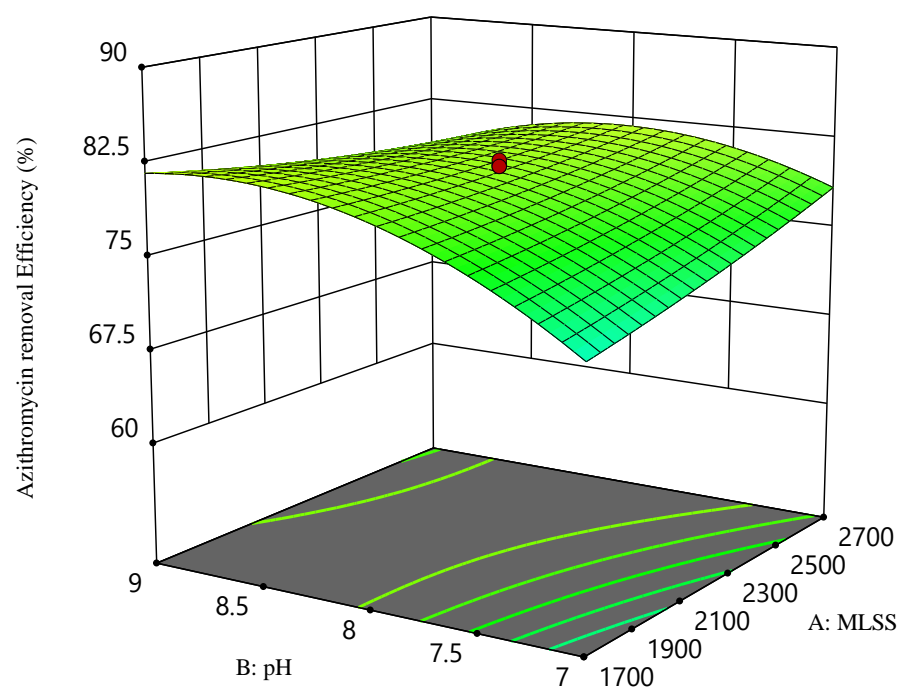

(ii)

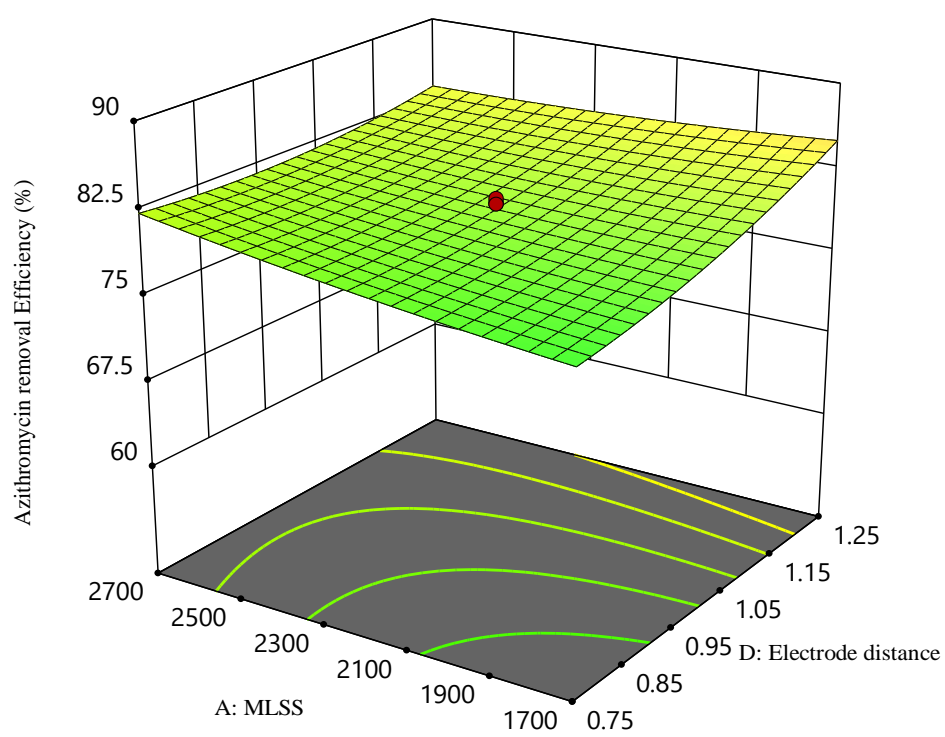

(iii)

Figure 1. 3D surface plots obtained from optimized values for the removal of Azithromycin removal percentage versus (i) pH vs. HRT; (ii) pH vs. MLSS; (iii) MLSS vs. Electrode distance. 


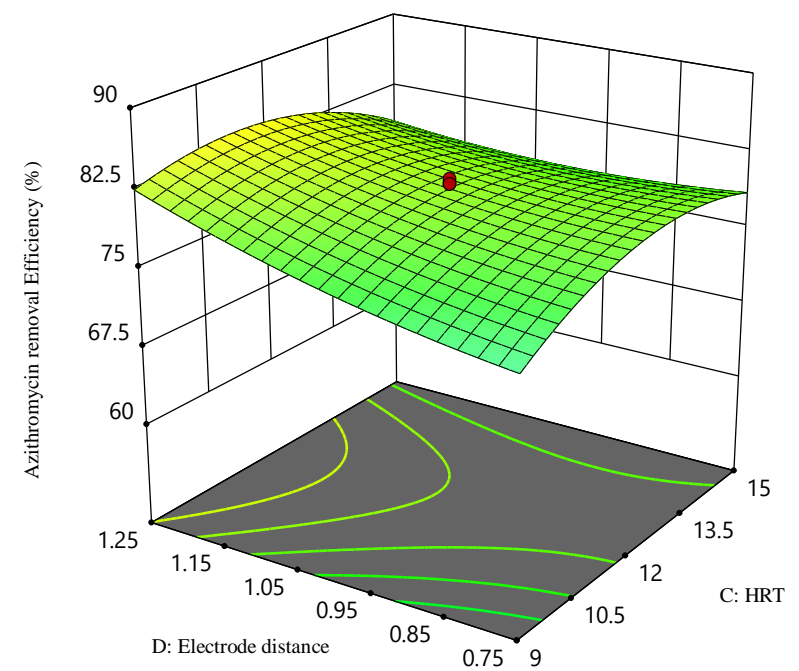

(i)

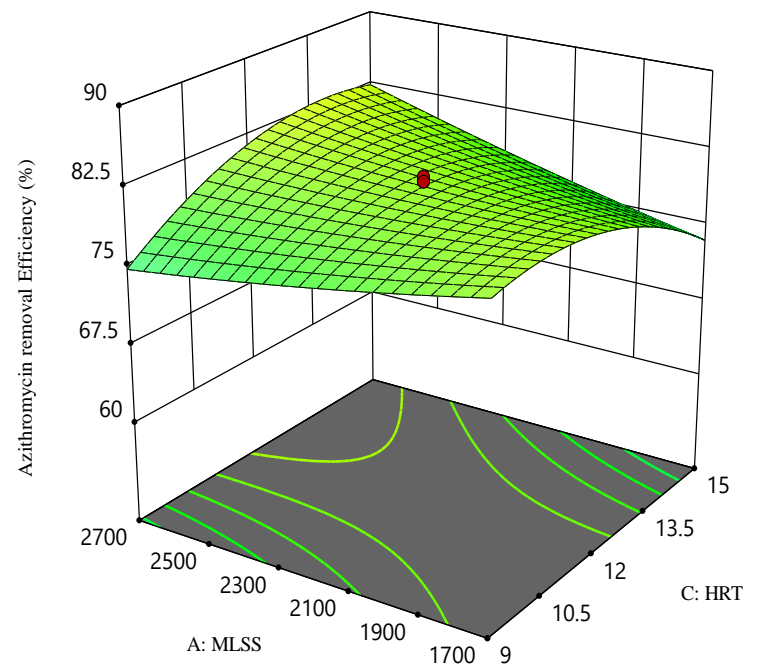

(ii)

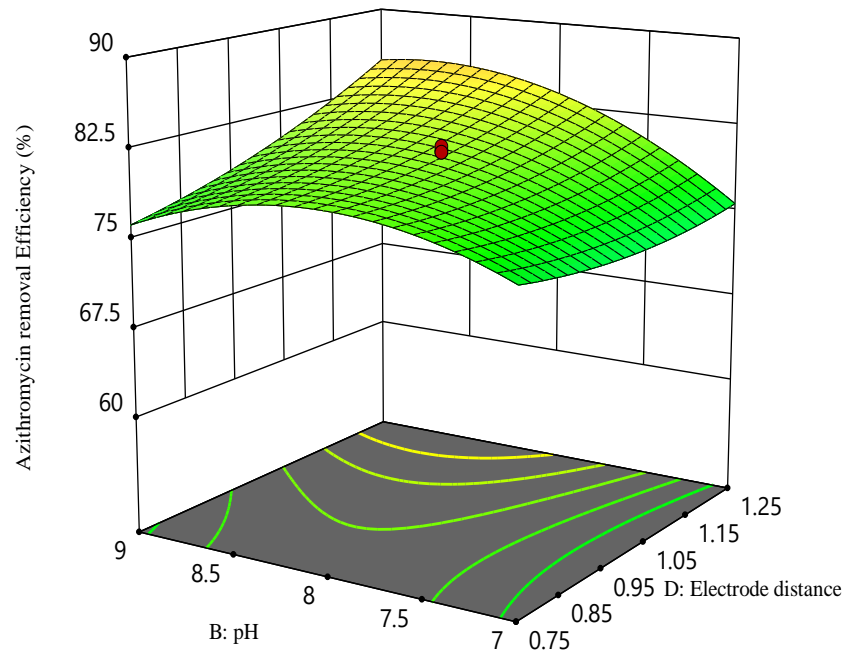

(iii) 


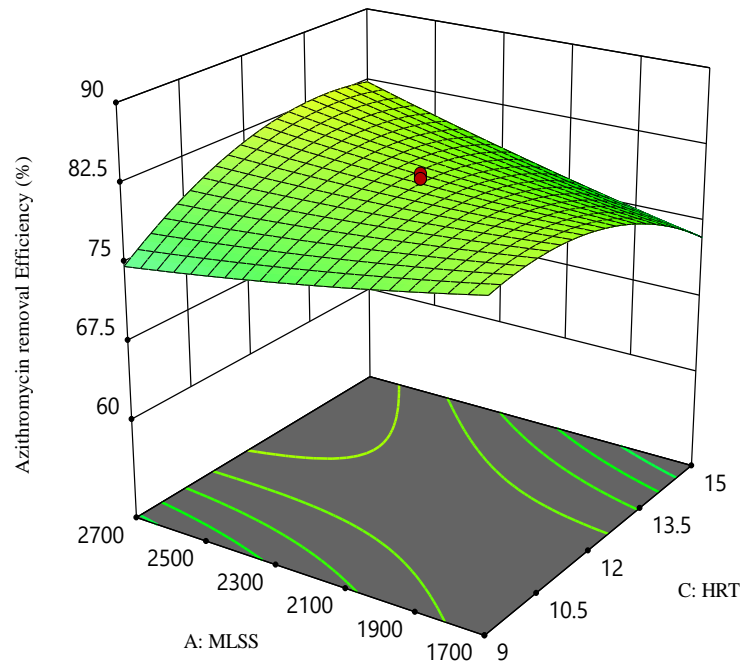

(iv)

Figure 2. 3D surface plots obtained from optimized values for the removal of Azithromycin removal percentage versus (i) Electrode distance vs. HRT (ii) MLSS vs. HRT (iii) pH vs. Electrode distance; (iv) MLSS vs. HRT.

\subsection{Effect of voltage and electrode distance.}

In addition, electrolytes can reduce COD amounts by $89 \%$ in the electrocoagulation phase; the contact period was another vector affecting COD decay. The effect was a long interaction duration between coagulants and waste pollutants, which reduces larger AZX. Electrocoagulation typically consists of adsorptive particle flocculation, whereby coagulants accumulate negative ions in waste materials, including nitrates, phosphates, nitrates, and other organic compounds, in a positive electromagnetic charge and form flocculation's, which tend to reduce AZX. This is what is happening. The longer electrolyze cycle of the Al electrode increases the production of hydroxide clusters in metals that can neutralize the surface floc.

The said model shows an F-value of about 63.2, which shows the model has a good level of significance. It is also attributed from the said results that $0.01 \%$ chance of F-value due to noise. The $\mathrm{P}$-value was seen to be 0.5 shows that the following interactions were significant, i.e., A, B, D, AB, AC, AD, BC, BD, CD, B ${ }^{2}, \mathrm{C}^{2}$, $\mathrm{D}^{2}$ in model terms. The values are higher than 0.1 attributed to the low significance of interaction terms. The lack of fit value was seen to be 1.83 , which signifies that the error is not high. There was a $26.23 \%$ chance that F-value having a higher value might occure due $t$ the noise and hence model seems to fit well.

The figure shown shows that the percent COD drop was affected considerably by three independent factors (contact time, voltage, and electrolyte). The quantity of oxygen required for oxidation of all organic substances utilizing a powerful oxidizer is COD (Chemical Oxygen Demand). The voltage is $6 \mathrm{~V}, 9 \mathrm{~V}$, and $12 \mathrm{~V}$ in this study, and the time as per the optimized condition used was $15 \mathrm{~min}, 30 \mathrm{~min}$, and $45 \mathrm{~min}$ in an electrochemical process. Anode of aluminum will be oxidated by an $\mathrm{Al}^{3+}$ reaction which reacts with the $\mathrm{Al}(\mathrm{OH})_{3}$ form. $\mathrm{Al}(\mathrm{OH})_{3}$. This alone is a coagulant capable of binding dissolved and suspended pollutants into the solution. Higher voltage leads to the high formation of coagulant used in the electrocoagulation process, and the ideal voltage observed was $12 \mathrm{~V}$. The reduction in COD in electrocoagulation is determined not only by the voltage but also by the electrolyte and the duration of contact. Electrolytes are used as a catalyst in the electrocoagulation process. In the electrocoagulation process, the inclusion of electrolytes will reduce COD by up to $89 \%$. Contact time is another component affecting COD reduction. Extended contact duration leads to extended interaction between waste coagulants and pollutants, reducing the amount of COD. Electrocoagulation is 
usually an adsorption particle flocculation where the coagulant absorbs negatives ions from waste materials such as nitrates, phosphates, nitrates, and other organic compounds at positive charged electrocoagulation and forms flocs materials that aid in the COD reduction process. The result indicates that, with the more extended period of electrolysis, the forming of hydroxide clusters in the surface of the metal is increased by the Al electrode.

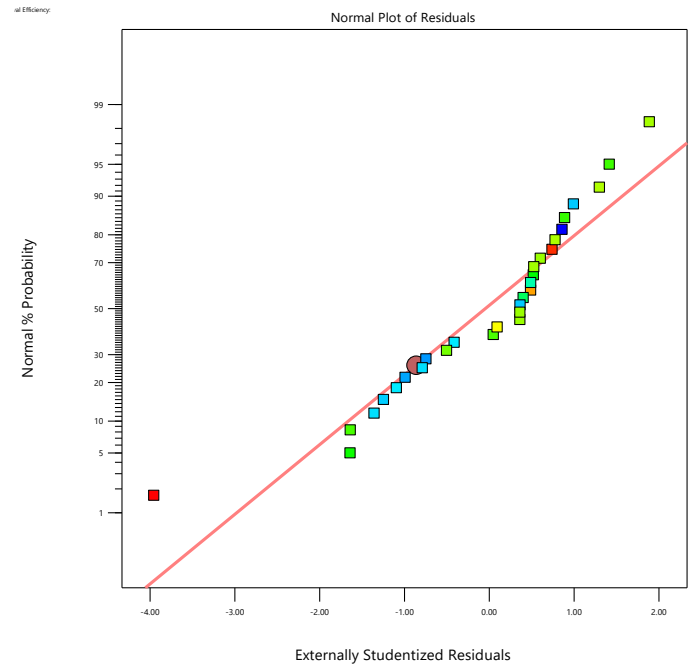

(i)

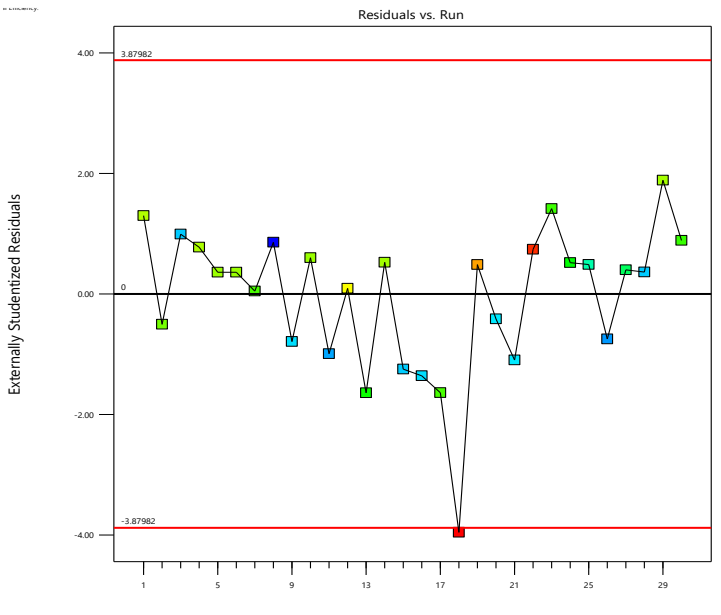

(ii)

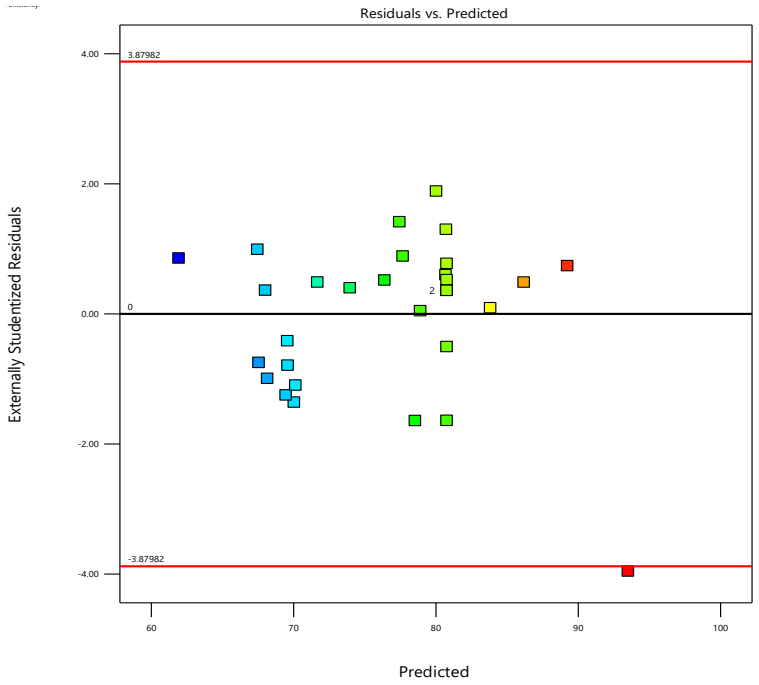

(iii) 


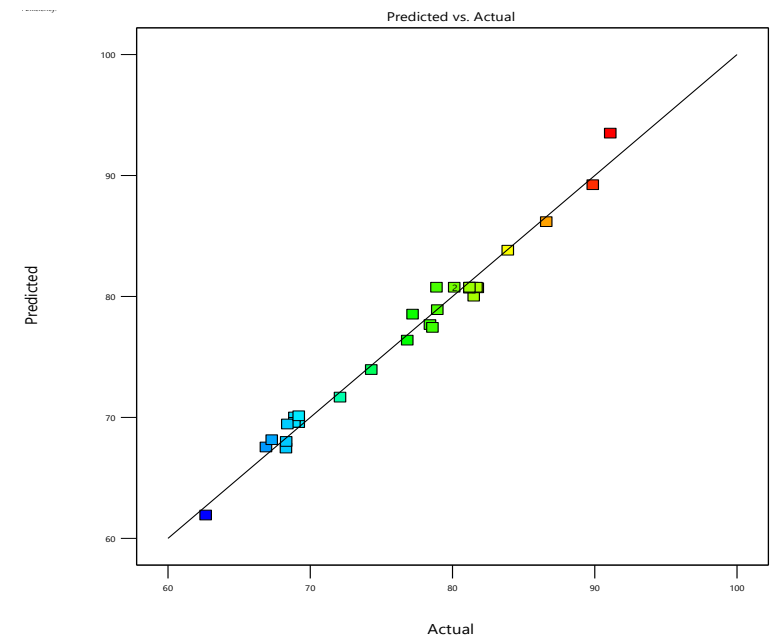

(iv)

Figure 3. ANOVA plots obtained from model parameters for the removal of AZX \% (i) Normal Plots; (ii) Residual vs. Run; (iii) residue vs. predicated; (iv) predicted vs. actual values.

\section{Conclusions}

The MBBR method, along with electrocoagulation can remove AZX from hospital wastewater exceptionally efficiently. The CCD method proved a helpful tool utilizing a surface response analysis to determine optimum conditions. The optimization analysis included three variables, i.e., packaging rate, HRT, and MLSS concentration. The findings showed that the removal performance of AZX and COD utilizing the media was $92.3 \%$ and $95.8 \%$, respectively, for 24 hours of retention and MLSS concentration of around $3000 \mathrm{mg} / \mathrm{l}$. This analysis indicates that the MBBR method was a promising strategy for wastewater treatment and AZX-containing aqueous solution. This study examines the efficiency of electrocoagulation in the treatment of hospital wastewater. The most important answer to this research is the efficiency of COD elimination. The investigation uses the central composite design Design Response Surface (RSM) approach for experimental data interaction. ANOVA gives the $\mathrm{R}^{2}$ values to validate the quadratic processes.

\section{Funding}

This research received no external funding.

\section{Acknowledgments}

The authors are thankful to Jamia Millia Islamia, New Delhi, for providing help and support during this work.

\section{Conflicts of Interest}

The authors declare no conflict of interest.

\section{References}

1. Chandrashekar Kollarahithlu, S.; Balakrishnan, R.M. Adsorption of pharmaceuticals pollutants, Ibuprofen, Acetaminophen, and Streptomycin from the aqueous phase using amine functionalized superparamagnetic silica nanocomposite. Journal of Cleaner Production 2021, 294, 126155, https://doi.org/10.1016/j.jclepro.2021.126155. 
2. Cao, S.-S.; Duan, Y.-P.; Tu, Y.-J.; Tang, Y.; Liu, J.; Zhi, W.-D.; Dai, C. Pharmaceuticals and personal care products in a drinking water resource of Yangtze River Delta Ecology and Greenery Integration Development Demonstration Zone in China: Occurrence and human health risk assessment. Sci. Total Environ. 2020, 721, 137624, https://doi.org/10.1016/j.scitotenv.2020.137624.

3. World Health Organization. Pharmaceuticals in drinking-water. 2012, 35, https://www.who.int/water_sanitation_health/publications/2011/pharmaceuticals_20110601.pdf.

4. Capoor, M.R.; Parida, A. Current perspectives of biomedical waste management in context of COVID-19". Indian J. Med. Microbiol. 2021, 39, 171-178, https://doi.org/10.1016/j.ijmmb.2021.03.003.

5. Majumder, A.; Gupta, A.K.; Ghosal, P.S.; Varma, M. A review on hospital wastewater treatment: A special emphasis on occurrence and removal of pharmaceutically active compounds, resistant microorganisms, and SARS-CoV-2. Journal of Environmental Chemical Engineering 2021, 9, 104812 , https://doi.org/10.1016/j.jece.2020.104812.

6. Prasanna, B.; Padmini, V.; Navle, K.; Dometti, H.S.; Moodu, S. Analysis of drugs in aquatic environment. 2015, 7, 71-79.

7. González Alonso, S.; Catalá, M.; Maroto, R.R.; Gil, J.L.R.; de Miguel, Á.G.; Valcárcel, Y. Pollution by psychoactive pharmaceuticals in the Rivers of Madrid metropolitan area (Spain). Environ. Int. 2010, 36, 195201, https://doi.org/10.1016/j.envint.2009.11.004.

8. de Voogt, P.; Janex-Habibi, M.L.; Sacher, F.; Puijker, L.; Mons, M. Development of a common priority list of pharmaceuticals relevant for the water cycle. Water Sci. Technol. 2009, 59, 39-46, https://doi.org/10.2166/wst.2009.764.

9. Lin, A.Y.-C.; Tsai, Y.-T. Occurrence of pharmaceuticals in Taiwan's surface waters: Impact of waste streams from hospitals and pharmaceutical production facilities. Sci. Total Environ. 2009, 407, 3793-3802, https://doi.org/10.1016/j.scitotenv.2009.03.009.

10. Almeida, Â.; Calisto, V.; Esteves, V.I.; Schneider, R.J.; Soares, A.M.V.M.; Figueira, E.; Freitas, R. Presence of the pharmaceutical drug carbamazepine in coastal systems: Effects on bivalves. Aquat. Toxicol. 2014, 156, 74-87, https://doi.org/10.1016/j.aquatox.2014.08.002.

11. Kümmerer, K. Antibiotics in the aquatic environment - A review - Part II. Chemosphere 2009, 75, 435-441, https://doi.org/10.1016/j.chemosphere.2008.12.006.

12. Graham, D.W.; Olivares-Rieumont, S.; Knapp, C.W.; Lima, L.; Werner, D.; Bowen, E. Antibiotic Resistance Gene Abundances Associated with Waste Discharges to the Almendares River near Havana, Cuba. Environ. Sci. Technol. 2011, 45, 418-424, https://doi.org/10.1021/es102473z.

13. Cooper, E.R.; Siewicki, T.C.; Phillips, K. Preliminary risk assessment database and risk ranking of pharmaceuticals in the environment. Sci. Total Environ. 2008, 398, 26-33, https://doi.org/10.1016/j.scitotenv.2008.02.061.

14. Zhang, Y.; Geißen, S.-U.; Gal, C. Carbamazepine and diclofenac: Removal in wastewater treatment plants and occurrence in water bodies. Chemosphere 2008, 73, 1151-1161, https://doi.org/10.1016/j.chemosphere.2008.07.086.

15. Mussa, Z.H.; Al-Qaim, F.F.; Othman, M.R.; Abdullah, M.P. Removal of simvastatin from aqueous solution by electrochemical process using graphite-PVC as anode: A case study of evaluation the toxicity, kinetics and chlorinated by-products. Journal of Environmental Chemical Engineering 2016, 4, 3338-3347, https://doi.org/10.1016/j.jece.2016.07.006.

16. Sirés, I.; Brillas, E.; Oturan, M.A.; Rodrigo, M.A.; Panizza, M. Electrochemical advanced oxidation processes: today and tomorrow. A review. Environmental Science and Pollution Research 2014, 21, 83368367, https://doi.org/10.1007/s11356-014-2783-1.

17. Fallah, Z.; Zare, E.N.; Ghomi, M.; Ahmadijokani, F.; Amini, M.; Tajbakhsh, M.; Arjmand, M.; Sharma, G.; Ali, H.; Ahmad, A.; Makvandi, P.; Lichtfouse, E.; Sillanpää, M.; Varma, R.S. Toxicity and remediation of pharmaceuticals and pesticides using metal oxides and carbon nanomaterials. Chemosphere 2021, 275, 130055, https://doi.org/10.1016/j.chemosphere.2021.130055.

18. Shan, D.; Deng, S.; Li, J.; Wang, H.; He, C.; Cagnetta, G.; Wang, B.; Wang, Y.; Huang, J.; Yu, G. Preparation of porous graphene oxide by chemically intercalating a rigid molecule for enhanced removal of typical pharmaceuticals. Carbon 2017, 119, 101-109, https://doi.org/10.1016/j.carbon.2017.04.021.

19. Jureczko, M.; Kalka, J. Cytostatic pharmaceuticals as water contaminants. Eur. J. Pharmacol. 2020, 866, 172816, https://doi.org/10.1016/j.ejphar.2019.172816. 
20. Mutiyar, P.K.; Gupta, S.K.; Mittal, A.K. Fate of pharmaceutical active compounds (PhACs) from River Yamuna, India: An ecotoxicological risk assessment approach. Ecotoxicol. Environ. Saf. 2018, 150, 297-304, https://doi.org/10.1016/j.ecoenv.2017.12.041.

21. Johnson, A.C.; Jürgens, M.D.; Su, C.; Zhang, M.; Zhang, Y.; Shi, Y.; Sweetman, A.; Jin, X.; Lu, Y. Which commonly monitored chemical contaminant in the Bohai region and the Yangtze and Pearl Rivers of China poses the greatest threat to aquatic wildlife? Environ. Toxicol. Chem. 2018, 37, 1115-1121, https://doi.org/10.1002/etc.4042.

22. Zhou, S.; Di Paolo, C.; Wu, X.; Shao, Y.; Seiler, T.-B.; Hollert, H. Optimization of screening-level risk assessment and priority selection of emerging pollutants - The case of pharmaceuticals in European surface waters. Environ. Int. 2019, 128, 1-10, https://doi.org/10.1016/j.envint.2019.04.034.

23. Bu, Q.; Wang, B.; Huang, J.; Deng, S.; Yu, G. Pharmaceuticals and personal care products in the aquatic environment in China: A review. J. Hazard. Mater. 2013, 262, 189-211, https://doi.org/10.1016/j.jhazmat.2013.08.040.

24. González-Alonso, S.; Merino, L.M.; Esteban, S.; López de Alda, M.; Barceló, D.; Durán, J.J.; LópezMartínez, J.; Aceña, J.; Pérez, S.; Mastroianni, N.; Silva, A.; Catalá, M.; Valcárcel, Y. Occurrence of pharmaceutical, recreational and psychotropic drug residues in surface water on the northern Antarctic Peninsula region. Environ. Pollut. 2017, 229, 241-254, https://doi.org/10.1016/j.envpol.2017.05.060.

25. Ercan, Ö.; Deniz, S.; Yetimoğlu, E.K.; Aydın, A. Degradation of Reactive Dyes Using Advanced Oxidation Method. CLEAN - Soil, Air, Water 2015, 43, 1031-1036, https://doi.org/10.1002/clen.201400195.

26. Le Corre, K.S.; Ort, C.; Kateley, D.; Allen, B.; Escher, B.I.; Keller, J. Consumption-based approach for assessing the contribution of hospitals towards the load of pharmaceutical residues in municipal wastewater. Environ. Int. 2012, 45, 99-111, https://doi.org/10.1016/j.envint.2012.03.008.

27. Verlicchi, P.; Al Aukidy, M.; Galletti, A.; Petrovic, M.; Barceló, D. Hospital effluent: Investigation of the concentrations and distribution of pharmaceuticals and environmental risk assessment. Sci. Total Environ. 2012, 430, 109-118, https://doi.org/10.1016/j.scitotenv.2012.04.055.

28. DeWitte, B.; Dewulf, J.; Demeestere, K.; Van De Vyvere, V.; De Wispelaere, P.; Van Langenhove, H. Ozonation of Ciprofloxacin in Water: HRMS Identification of Reaction Products and Pathways. Environ. Sci. Technol. 2008, 42, 4889-4895, https://doi.org/10.1021/es8000689.

29. Kimura, K.; Hara, H.; Watanabe, Y. Elimination of Selected Acidic Pharmaceuticals from Municipal Wastewater by an Activated Sludge System and Membrane Bioreactors. Environ. Sci. Technol. 2007, 41, 3708-3714, https://doi.org/10.1021/es061684z.

30. Bushra, R.; Aslam, N. An overview of clinical pharmacology of Ibuprofen. Oman Med. J. 2010, 25, 155, https://doi.org/10.5001/omj.2010.49.

31. Verlicchi, P.; Galletti, A.; Petrovic, M.; Barceló, D. Hospital effluents as a source of emerging pollutants: An overview of micropollutants and sustainable treatment options. Journal of Hydrology 2010, 389, 416-428, https://doi.org/10.1016/j.jhydrol.2010.06.005.

32. Lambropoulou, D.; Evgenidou, E.; Saliverou, V.; Kosma, C.; Konstantinou, I. Degradation of venlafaxine using TiO2/UV process: Kinetic studies, RSM optimization, identification of transformation products and toxicity evaluation. J. Hazard. Mater. 2017, 323, 513-526, https://doi.org/10.1016/j.jhazmat.2016.04.074.

33. Carraro, E.; Bonetta, S.; Bertino, C.; Lorenzi, E.; Bonetta, S.; Gilli, G. Hospital effluents management: Chemical, physical, microbiological risks and legislation in different countries. J. Environ. Manage. 2016, 168, 185-199, https://doi.org/10.1016/j.jenvman.2015.11.021.

34. Rtimi, S.; Giannakis, S.; Bensimon, M.; Pulgarin, C.; Sanjines, R.; Kiwi, J. Supported TiO2 films deposited at different energies: Implications of the surface compactness on the catalytic kinetics. Applied Catalysis B: Environmental 2016, 191, 42-52, https://doi.org/10.1016/j.apcatb.2016.03.019.

35. Chonova, T.; Keck, F.; Labanowski, J.; Montuelle, B.; Rimet, F.; Bouchez, A. Separate treatment of hospital and urban wastewaters: A real scale comparison of effluents and their effect on microbial communities. Sci. Total Environ. 2016, 542, 965-975, https://doi.org/10.1016/j.scitotenv.2015.10.161.

36. Papoutsakis, S.; Miralles-Cuevas, S.; Oller, I.; Garcia Sanchez, J.L.; Pulgarin, C.; Malato, S. Microcontaminant degradation in municipal wastewater treatment plant secondary effluent by EDDS assisted photo-Fenton at near-neutral pH: An experimental design approach. Catal. Today 2015, 252, 61-69, https://doi.org/10.1016/j.cattod.2015.02.005.

37. Ahmad, S.; Mehfuz, S.; Beg, J.; Ahmad Khan, N.; Husain Khan, A. Fuzzy cloud based COVID-19 diagnosis assistant for identifying affected cases globally using MCDM. Materials Today: Proceedings 2021, https://doi.org/10.1016/j.matpr.2021.01.240. 
38. Yadav, V.K.; Yadav, K.K.; Cabral-Pinto, M.M.S.; Choudhary, N.; Gnanamoorthy, G.; Tirth, V.; Prasad, S.; Khan, A.H.; Islam, S.; Khan, N.A. The Processing of Calcium Rich Agricultural and Industrial Waste for Recovery of Calcium Carbonate and Calcium Oxide and Their Application for Environmental Cleanup: A Review. Applied Sciences 2021, 11, https://doi.org/10.3390/app11094212.

39. Kozub, P.; Kozub, S.; Mozaffari, N.; Sihag, P.; Mozaffari, N.; Vambol, S.; Vambol, V.; Ramsawak, N.; Khan, N.A. Treatment schemes - conventional and dedicated for PhACs treatment. In Pharmaceutical Wastewater Treatment Technologies: Concepts and Implementation Strategies, IWA Publishing: 2021; https://doi.org/10.2166/9781789061338_0181.

40. Khan, A.H.; Aziz, H.A.; Khan, N.A.; Hasan, M.A.; Ahmed, S.; Farooqi, I.H.; Dhingra, A.; Vambol, V.; Changani, F.; Yousefi, M.; Islam, S.; Mozaffari, N.; Mahtab, M.S. Impact, disease outbreak and the ecohazards associated with pharmaceutical residues: a Critical review. Int. J. Environ. Sci. Technol. (Tehran) 2021, https://doi.org/10.1007/s13762-021-03158-9.

41. Mazhar, M.A.; Khan, N.A.; Khan, A.H.; Ahmed, S.; Siddiqui, A.A.; Husain, A.; Rahisuddin; Tirth, V.; Islam, S.; Shukla, N.K.; Changani, F.; Yousefi, M.; Hassaballa, A.E.; Radwan, N. Upgrading combined anaerobicaerobic UASB-FPU to UASB-DHS system: Cost comparison and performance perspective for developing countries. Journal of Cleaner Production 2021, 284, 124723, https://doi.org/10.1016/j.jclepro.2020.124723.

42. Khan, R.; Khan, S.; Islam, S.; Nazar, S.; Khan, N. Comparative study of Compressive and Tensile Behaviour of Polypropylene Fibre Reinforced Concrete (PFRC) of M15 and M20 Mix. International Journal of Engineering Associates 2015, 4, 26-29.

43. Alsubih, M.; El morabet, R.; Khan, R.A.; Khan, N.A.; Khan, A.R.; Sharma, G. Performance evaluation of aerobic fluidized bed bioreactor coupled with tube-settler for hospital wastewater treatment. Journal of Environmental Chemical Engineering 2021, 9, 105896, https://doi.org/10.1016/j.jece.2021.105896.

44. Khan, N.A.; Khan, S.U.; Ahmed, S.; Farooqi, I.H.; Dhingra, A.; Hussain, A.; Changani, F. Applications of nanotechnology in water and wastewater treatment: A review. Asian Journal of Water, Environment and Pollution 2019, 16, 81-86, https://doi.org/10.3233/AJW190051. 